\title{
Changes of Ocean Level
}

\author{
The Isostatic Subsidence of Volcanic Islands
}

\author{
By W. M. Davis, Harvard University
}

Objection has sometimes been made to Darwin's theory of upgrowing coral reefs on subsiding foundations on the ground that the subsidence of the ree foundations should lower the ocean surface and lay bare a belt of recent marine deposits of smooth surface and simple shore line around the continental masses, while as a matter of fact the shore lines of continents are usually more or less embayed, as if the sea had recently advanced upon the unevenly eroded surface of the continental margins. The objection will, however be found to have small weight when it is seen to rest upon the implie postulate that the embayments of continental coasts have as a rule been produced by a continental coasts have as a rule been produced by
universal rise of the ocean surface, everywhere of the universal rise of the ocean surface, everywhere of the
same amount and date, whereas their embayments tessame amount and date, whereas their embayments tes-
tify to no such simple origin; and to proceed upon the unwarranted assumption that the subsidence of ree foundations requires the subsidence of broad areas of the ocean floors, whereas the local subsidence of the foundations themselves is all that is necessary.

The embayment of continental coasts is certainly of widespread occurrence, but when the embayments are closely examined they are found to be of dates and mensions so diverse that they cannot be explained by a universal rise of the ocean. In the first place, th most pronounced embayments are the fiord coasts of quaternary glaciation; there is good reason to believe that the great troughs of such coasts were scoured out deep below sea level by huge glaciers, and that, far from the ocean having recently risen to submerge the troughs, the coasts have in several, fiord regions rise from the ocean, as their elevated shore lines testify these coasts are embayed in spite of recent emergence. Furthermore, the supposition that coastal embayments result from a rise of the ocean around stillstanding continental borders carries with it the impli cation that the coastal valleys, now submerged and embayed, were everywhere eroded during the same period of previous emergence, and hence that they should all be eroded to the same depth, and that their wilth should be proportionate to the weakness of the width should be proportionate to the weakness of the
rocks in which they were carved during the emergence rocks in which they were carver. But as a matter of fact, the coastal enibayments of the continents occupy valleys of depths an widths so various that they cannot be accounted for by these simple conditions; the diversity of the embayments demands many local and diverse movements of continental borders, even though a universal rise of ocean level has recently taken place, such as that which the final climatic changes at the close of the Glacia the final climatic changes at the close of the Glacial
period should produce. The chief effect of such a rise period should produce. The chief effect of such a rise
of ocean level would only be to bring about a slight preponderance of embayed coasts along continental borders which had suffered local uplifts and depression in about equal proportions.

Diverse movements of continental borders are de manded not only by the diversity of their embayments, but also by the not rare occurrence of emerged coasta plains of marine sediments. Thus the western side of the Adriatic is bordered by an emerged and more the Adriatic is bordered by an emerge and more or less dissected coastal plain, while the eastern side bayed mountain border. Greece and the Bosphor bear marks of recent submergence, but the coast of Palestine appears to bear marks of recent emergence The small embayments of the Texas coastal plain cannot be explained as resulting from the same amount of submergence which produced the deep rias in the mountainous coast of northwestern Spain; nor can the un tike valleys of those two coasts have been eroded durlike valleys of those two coasts have been eroded ur
ing the same antecedent period of emergence. The eleing the same antecedent period of emergence. The ele
vated shore lines of the California coast have no equivalent on the volcanic islands of the Pacific. The recent submergence of the northeastern coast of New Cale donia following a long-enduring emergence, as indicated by the deep embayments of its strongly clift shores, demands a different succession of changes of level from those recorded in Peru or Virginia.

The postulate that the embaye coasts of the world demand a universal rise of the ocean for their expla nation is largely based upon the indoor study of coastal charts, and not upon the field study of the coasts them selves; and inasmuch as most of the coastal charts of the world have been made by hydrographers, who concerned themselves little with the physiographic history of the coastal slope, such charts cannot be relied upon to present all the information that is pertinent to the problem under discussion.

* From the Proceedings of the National Academy of Sciences.
It occasionally happens, however, that a hydrographic hart presents evidence which suffices to correct a false inference regarding recent submergence; thus one f the Solomon islands, which has a well-embayed shor line, is fronted for many miles by an elevated off-shore barrier reef, even crested and 80 or 100 feet in height hence although the coastal embayments show that submergence has taken place, the reef shows that the last change of level was an emergence, less in amount than the previous submergence.

In view of these examples it is evident that the chart of an embayed coast, outside of the coral zone and not yet examined geologically, cannot be trusted as indicating that the last change of ocean level was upward. Therefore the inference that there has been a genera rise of ocean level, independent of oscillations during the Glacial period, is not at present well supported and until it is well supported, a certain amount of broad ocean-floor subsidence in the coral seas, as inferred by Darwin from this theory of coral reefs, may be regarded as not impossible, particularly as its effect in lowering the ocean may have been counteracted by in lowering the ocean may have been counteracted
equally broad ocean-floor uplifts in other regions.

Nevertheless, it is somewhat arbitrary to assume that the broad areas of ocean-floor subsidence should occur chiefly in the warmer zone, where coral reefs could be formed, and that the areas of compensating uplift should be chiefly in the cooler oceans, or in those parts of the warmer oceans where no islands rise. Hence the supposition of local subsidence of volcanic islands, which usually serve as reef foundations, deislands, which usually serve as reef foundations, de-
serves consideration as an alternative to broad oceanserves consideration as an alternative to broad ocean-
floor subsidence. This supposition would be objected to by scientists of the older school, who believed that volcanoes occupy areas of elevation. Thus Guppy said : "In establishing the fact of the presence of active volcanoes in regions of barrier reefs and atolls, I shall be removing one of the principal standpoints of the theory of subsidence;" he added that this "places the supporters of the theory of subsidence in a dilemna." 1 At about the same time Hickson wrote: "I am persuaded about the same time Hickson wrote: "I am persuaded
that ... the presence of such an atoll as Passiac [in North Celebes] so close to a region of quite recent and considerable volcanic activity is difficult to account for under this [subsidence] theory." Murray went so fas as to object to Darwin's theory of subsidence on the ground that even extinct volcanoes are not likely to subside. He wrote: "Generally speaking, all the volcanic regions which we know have in the main been areas of elevation, and we would expect the same to hold good in those vast and permanent hollows of the hold good in those vast and permanent hollows of the
earth which are occupied by the waters of the ocean. . Areas of local depression are to be looke for in the ocean basins on either side of and between groups of volcanic islands and atolls, and not on the very site of these islands."s

Much may be said against this obsolescent view, and in favor of the opposite view that volcanic action and to sometimes be closely associated. Strong testimony to this effect is offered by the repeated oc-
currence of volcanic eruptions in areas of subsidence during the geological evolution of Great Britain, as worked out by an exceptionally competent geologist whose conclusion is: "The study of the records of volcanic action in Britain proves beyond dispute that the volcanoes of past time have been active in areas of the earth's surface that were sinking and not rising. . I do not wish to maintain that the downward movement was necessarily a consequence of volcanic ejections. . . . but I have sometimes asked myself whether it was not possibly increased as a sequel to
whentions. . but I have sometimes asked myself whether it was not possibly increased as a sequel to
vigorous action." " An interesting piece of evidence vigorous action." A An interesting piece of evidence
concerning the subsidence of the great volcanic island of Hawaii during the later stages of its eruptive growth is furnished by Branner, who gives good reason fo thinking that the deep canyons in the northeastern sector- of the island have been eroded in part of an older, deeply.dissected, and now partly submerged volcanic mass, the remainder of which has been overwhelmed: and buried: under more recent lava floods. ${ }^{5}$ The newest discussion of this problem is by Molen${ }^{1}$ Guppy, H. B., Scot. Geogr. Mag., 14, 1888, (121-137); see p. 135,136

7Hickson, S. J., A naturalist in Celebes, London, 1889

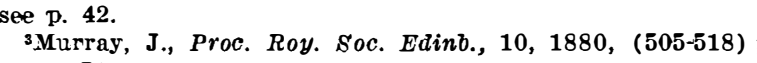
see p. 516.

4Gelkie, Sir A., The ancient volcanoes of Great Britain

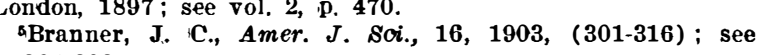
p. 301-303. graaf, who calls attention to the results of recent gravity determinations, from which it appears that the volcanic islands of the Pacific "as far as they" have been studied are not isostatically compensated, and, without exception, show a larger or smaller positive anomaly of gravity. ... These volcanic islands, rising .... as cones or groups of cones of considerable bulk, cannot always remain in existence; under the influence of gravity they will without exception yield and sink down slowly. ... The yielding and slow sinking of the volcanic islands under the influence of gravity must be regarded as the cause of the downward movemust be regarded as the cause of the downward move-
ment of large amount and long duration which must be assumed in order to explain the formation of barrierreefs and atolls in true oceanic regions."

This appears to me an important suggestion, and one that is likely to remove the objections to Darwin's theory of coral reefs in so far as they are directed against a great subsidence of broad ocean-floor coral-reef theory ito infer the subsidence of such areas, it is clear from the original exposition of his theory that local subsidence of reef foundations will serve all its needs. It may be added that the accumulation of the great limestone masses of atolls upon slowly sinking volcanic foundations must aid and prolong their sinking; also that no comparable sinking of volcanic cones upon continents need be expected, not only because of the differences supposed to exist between the earth's crust in continental and oceanic areas, to which Molengraaf calls attention, but also because continental volcanoes suffer erosion, whereby their waste is carried away and widely distributed, while oceanic volcanoes retain the waste from their summits on their flanks.

But it is particularly the relation of Molengraaf's hypothesis to changes of ocean level that I desire to emphasize. Let it be imagined that the ocean floor suffers no deformation apart from that associated with volcanic action, and that a thousand great volcanic cones are built up from it in the coral zone, one after the other and at such intervals of time that their formation stretches through the Tertiary and Posttertiary periods. The building of the first cone would cause a slight rise of ocean level. As the cone slowly subsided the ocean surface would return to its normal stand, were it not that the subsiding cone is reconstituted in an atoll as fast as it subsides," and that other cones are built up as the first one sinks. Later formed cones would prolong the changes thus initiated, and the slow rise of the ocean would continue, particularly if the isostatic sinking of some of the cones were incompletely accomplished. Even if some of the cones sank so fast that reef-making corals could not reconstitute them, the net result of this process, after many cones had been built up and sunk again, would be, not a lowering of the ocean surface such as according to the usual interpretation of the theory of subsidence has been supposed to accompany the upgrowth of coral reefs, but a slow and long continued rise of the ocean surface.

The rise of the ocean surface thus caused would be much less in total amount than the sinking, suffered by any one of the volcanic reef foundations, and hence less than the inferred great thickness of many atoll masses, but it would presumably be sufficient to cause a moderate preponderance of submergence on continental coasts which themselves suffer many diverse movements of upheaval and depression. It is not, however, to be supposed that general warpings and deformations of the ocean floor, upward and downward, should be left out of consideration; such movements have surely taken place to a less or greater degree, particularly in the western Pacific, where coral reefs border continental islands. The integrated effect of face cannot now be determined, because so little is known regarding the various factors of the problem; but nothing in the little that is known and in the much more that may be fairly inferred should be regarded as discountenancing the theory of upgrowing reefs on subsiding foundations, essentially as Darwin supposed. His primary theory of coral reefs holds
good, although his supplementary theory of broad ocean-floor subsidence needs modification.

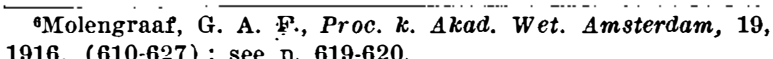

1916, (610-627); see p. 619-620.
7This statement depends on the fact, certified by chemists,
that the withdrawal of limestone from solutions in water that the withdrawal of limestone from solutions in water
diminishes the water volume by only a small portion of the volume of the withdrawn limestone.
the 